\title{
An Algorithm Based Approach To Ovarian Neoplasms
}

\section{ABSTRACT}

Introduction: Cancer of the ovaries is the $2^{\text {nd }}$ most common gynaecological malignancy and has the highest mortality rate among all gynaecological malignancies with an overall 5 year survival rate of $46 \%$. A large number of the lesions are incidentally detected, for which imaging plays a vital role in treatment planning by characterizing these masses. Identifying benign lesions accurately may obviate unnecessary surgery, where as indeterminate or malignant lesions will require surgery with or without radio/chemotherapy.

Aim: To inform the readers the imaging patterns of common and rarely encountered ovarian neoplasms and to provide an algorithm based approach to these ovarian lesions, which will not only aid in the management of these conditions but also obviate unnecessary investigations and surgeries.

Materials and Methods: This was a prospective study conducted over a period of one year from January 2014 to January 2015 at the Department of Radiology, Father Muller Medical College, Mangalore, India. Data were collected from 82 patients who presented with ovarian cystic lesions on ultrasound and were either followed up by USG or underwent further evaluation by CT. Diagnosis was confirmed by histopathology. Statistical analysis involved percentage frequency.

Results: Of the 82 patients included in the study, the largest age group belonged to the $3^{\text {rd }}$ decade $(41 \%)$. Patients belonging to the $6^{\text {th }}$ decade and above presented with the largest cases of ovarian cystic malignancies (61\%). On imaging, papillary projections, vascular solid components and thick septations $(>3 \mathrm{~mm})$ favoured malignancy. All cases of teratoma were accurately diagnosed (100\% accuracy) due to the presence of fat and calcifications.

Conclusion: Both Ultrasound and CT are excellent tools in the diagnosis of ovarian cystic masses. An algorithm based approach to ovarian masses allows early detection, saves time and unnecessary burden to the patients and their families. In addition imaging is also useful to identify the extent of the disease and pre-treatment planning.

\section{INTRODUCTION}

Gynaecological malignancies include cervical cancer, endometrial cancer, and ovarian cancer. Cancer of the ovaries is the $2^{\text {nd }}$ most common gynaecological malignancy and has the highest mortality rate among all. The overall 5 years survival rate for ovarian cancer despite therapeutic and diagnostic advances has changed little. Imaging plays a vital role in treatment planning by characterizing these masses in terms of benign vs. malignant [1]. In this article we inform the readers the imaging patterns of common and rarely encountered ovarian neoplasms and in addition we provide an algorithm based approach to these ovarian lesions, which will aid in the management and also avoid unnecessary investigations and surgeries.

\section{MATERIALS AND METHODS}

This was a prospective study conducted over a period of one year from January 2014 to January 2015 at the Department of Radiology, Father Muller Medical College, Mangalore, India. Father Muller Institutional Ethics Committee approval was obtained prior to the study and patient consents were obtained for use of their radiology images. Data from 82 patients (with an average mean age of 32.3 years) who presented with ovarian cystic lesions on ultrasound and followed up by USG or underwent further evaluation by CT/MRI were included in the study. Patients with a known ovarian primary neoplasm, allergy to contrast agents and those with no follow-up were excluded from this study. Patients belonging to the $3^{\text {rd }}$ and $4^{\text {th }}$ decade age groups 
formed the bulk of our patients $41 \%$ and $22 \%$ respectively. While the least portion of our patients belonged to the $8^{\text {th }}$ and $7^{\text {th }}$ decade age group, $1 \%$ and $4 \%$ respectively.

All patients were initially evaluated by ultrasound (Philips $\mathrm{IU}-22)$ by an experienced sonologist using standardized examination techniques, terms and definitions. A Transvaginal Sonography (TVS) was performed in all cases, except in unmarried women and those who were not willing. Transabdominal Sonography (TAS) was used to examine larger lesions that could not be seen entirely on TVS. All lesions were evaluated further by colour Doppler to assess the vascularity.

In those patients who underwent further evaluation by MDCT (GE BrightSpeed 16 Slice scanner), initial plain abdominal CT images were acquired by at $120 \mathrm{kV}$ and $200 \mathrm{mAs}$ to determine baseline HU value and to look for any calcifications. Post contrast images were obtained after administration of $90 \mathrm{ml}$ of non- iodinated contrast (350 mg\% w/v) injected at the rate of $3 \mathrm{ml} /$ second with the help of a Mallinckrodt pressure injector. Arterial and porto-venous phase images were acquired at 18-22 sec and 60-65 sec respectively. 3D reconstruction using thin sections $(1 \mathrm{~mm})$ were performed in coronal and sagittal planes for better depiction of the lesion and its extent and involvement of adjacent structures.

Patients who underwent MR evaluation, images were obtained by PHILIPS ACHIEVA 1.5 T scanner with the use of a small field of view $(20 \mathrm{~cm})$, high-resolution matrixes $(256 \times 256)$, and thin sections $(4 \mathrm{~mm})$. For an adequate MR pelvic examination, $\mathrm{T} 1-\mathrm{Wl}$ in axial plane and T2-WI were obtained in axial, sagittal and coronal planes for evaluation of uterus, adjacent organs, pelvic floor and broad ligaments. T1 fat suppressed images were obtained to identify blood and fat, while T2 fat suppressed images were employed to identify edema or inflammatory changes. Post Gadolinum T1-WI were used to identify enhancing ovarian solid components, septae, peritoneal and omental deposits and visceral metastases. The final diagnosis was confirmed by histopathology. Statistical analysis involved percentage frequency.

\section{RESULTS}

82 patients formed the sample size of our study. The average mean age was 32.3. The number of patients belonging to the different age groups were- $3^{\text {rd }}$ decade: $n=34(41 \%) ; 4^{\text {th }}$ decade: $n=18(22 \%) ; 5^{\text {th }}$ decade: $n=6(7 \%) ; 6^{\text {th }}$ decade: $n=8$ (10\%); $7^{\text {th }}$ decade: $n=3(4 \%) ; 8^{\text {th }}$ decade: $n=1$ (1\%) [Table/ Fig- 1].

The various pathological cysts in our study includedHaemorrhagic cysts $(n=32)$, Endometriotic cysts $(n=20)$, Serous Cystadenoma/ Cystadenocarcinoma ( $n=15)$, Mucinous Cystadenoma/ Cystadenocarcinoma $(n=7)$,
Dysgerminoma $(n=1)$, Mature cystic teratoma $(n=3)$, Kruckenberg tumor ( $n=3)$, Non Hodgkins Lymphoma $(n=1)$. [Table/Fig-2].

Unilocular, anechoic, simple cysts (no septations/ solid components) measuring $<5 \mathrm{~cm}$ in diameter seen on USG

\begin{tabular}{|c|c|c|}
\hline Age Group & Frequency & Percentage \\
\hline $10-19$ & 12 & 15 \\
\hline $20-29$ & 34 & 41 \\
\hline $30-39$ & 18 & 22 \\
\hline $40-49$ & 6 & 7 \\
\hline $50-59$ & 8 & 10 \\
\hline $60-69$ & 3 & 4 \\
\hline $70-79$ & 1 & 1 \\
\hline \\
[Table/Fig-1]: Frequency and percentage of ovarian cystic lesions \\
seen in various age groups.
\end{tabular}

\begin{tabular}{|l|c|}
\hline \multicolumn{1}{|c|}{ Pathological Cysts } & Frequency \\
\hline 1. Hemorhagic cysts & 32 \\
\hline 2. Endometriotic cysts & 20 \\
\hline $\begin{array}{l}\text { 3. Serous Cystadenorma } \\
\text { Cystadenoma/Cystadenocaricnoma }\end{array}$ & 15 \\
\hline - Dysgernminoma & 7 \\
\hline - Mature cystic teratoma & 1 \\
\hline 6. Ovarian Metastases & 3 \\
\hline - Kruckenberg & 3 \\
\hline - Non-Hodgkins Lymphoma & 1 \\
\hline [Table/Fig-2]: Frequency of various ovarian cystic pathologies seen \\
in our study.
\end{tabular}

are unlikely to be malignant. Cysts of $1-7 \mathrm{~cm}$ size should be followed up by USG yearly to assess stability. If $>7 \mathrm{~cm}$, the lesion should be evaluated surgically or further imaging by $\mathrm{CT} / \mathrm{MRI}$ is required. Complex cystic lesions with solid components/ mural nodules/ thick irregular septae on USG should raise the suspicion of malignancy, and therefore requires serum marker (CA-125) and surgical evaluation. These patients may undergo additional imaging by CT/ $\mathrm{MRI}$ preoperatively to characterize the lesion and assess disease extent or following surgery to assess the progress of treatment (radiotherapy/ chemotherapy). An ovarian cyst with internal echoes, foci of calcification or fluid-fluid level is likely to be a dermoid or teratoma. An incidentally detected lesion on CT/MRI with area of fat attenuation, calcification and fat fluid level is diagnostic of a dermoid. Based on our results and the lesion characteristics on the various imaging modalities (USG, CT, MRI) an imaging based algorithm was formulated for approaching ovarian neoplastic lesions, which has been outlined in [Table/Fig-3,4], for pre and post menopausal women respectively. 


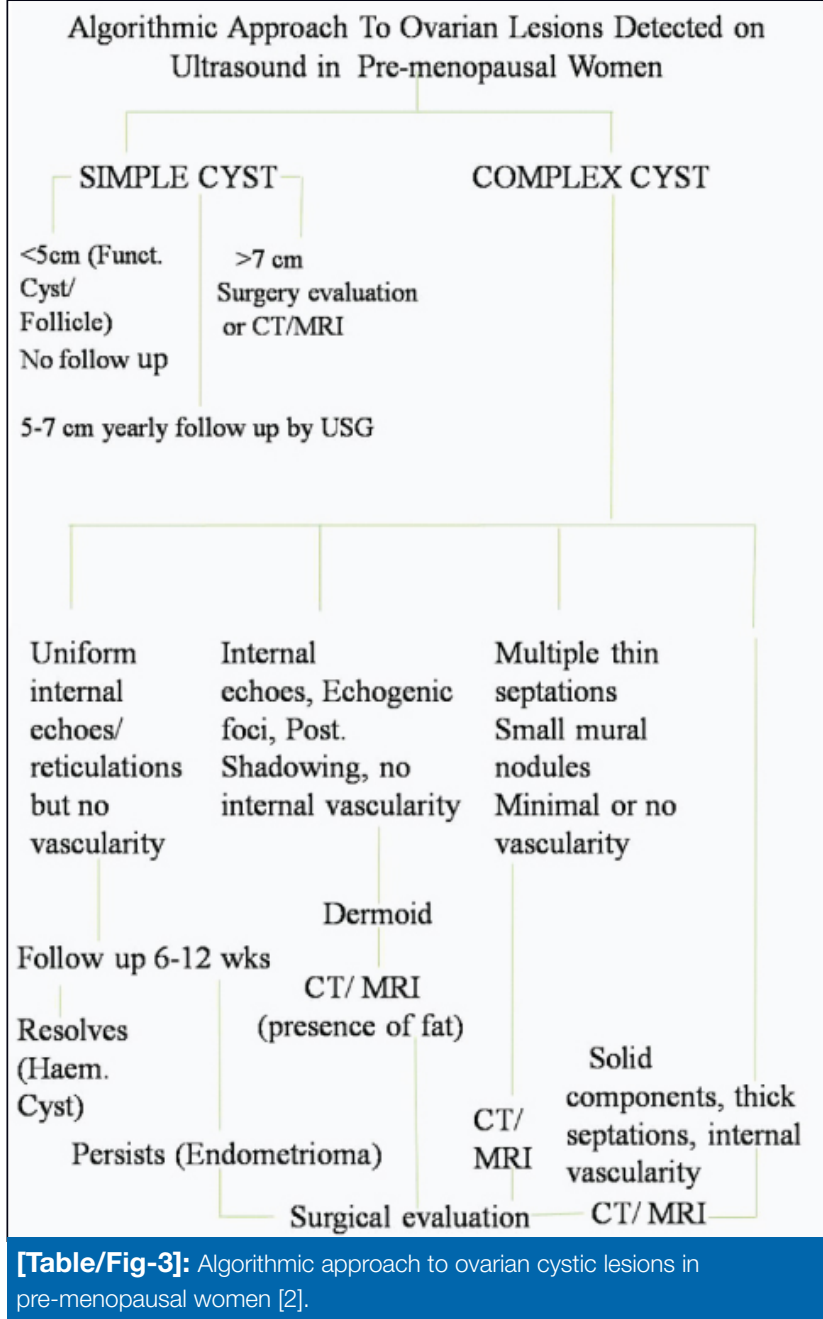

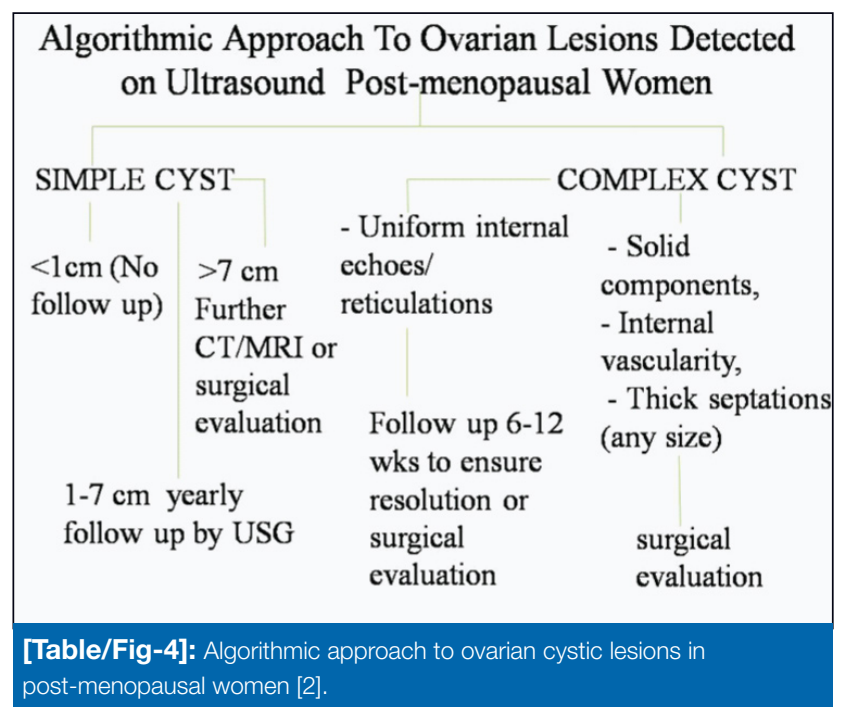

\section{DISCUSSION}

Various imaging modalities available for evaluation ovarian lesions includes Ultrasound, CT, MRI, PET etc. We elaborate the imaging patterns of different ovarian lesions on various modalities, including their advantages and disadvantages in detail below.

\section{Ultrasonography (USG)}

USG is the main modality of choice for evaluating pelvic lesions. Its advantages includes low cost, easy availability, lack of ionizing radiation, high sensitivity, and short duration for the examination. On color Doppler malignant lesions maybe differentiated from benign lesions, with the former having low resistance index $(\mathrm{Rl})$. A $\mathrm{Rl}$ of $<0.4$ and and $\mathrm{a}$ pulsatality index $(\mathrm{PI})$ of $<1.0$ favours malignancy. However Doppler USG has limitations as there is considerable overlap of findings between benign and malignant conditions [3]. Disadvantages of USG include its operator dependency and images being affected by patient's body habitus [4].

\section{Computed Tomography (CT)}

The role of CT in characterizing and evaluating ovarian cystic lesions is limited, except for mature cystic teratomas which show areas of fat density and calcifications. Nevertheless CT is the modality of choice for assessing extent of the disease, pre-treatment planning, as well as for follow-up. CT has a sensitivity and specificity of $50 \%$ and $92 \%$ respectively in the staging of ovarian carcinoma [5].

\section{Magnetic Resonance Imaging (MRI)}

When compared with CT, MRI has better tissue characterization and multiplanar capabilities with anatomical delineation. In most case contrast enhanced MRI allows differentiation between benign and malignant ovarian cystic lesions [6]. For sonologically indeterminate lesions, MRI reportedly has a sensitivity and specificity of about $100 \%$ and $94 \%$ respectively [7]. Due to its high cost and limited availability it's often used as a problem solving tool in indeterminate lesions.

\section{Positron Emission Tomography (PET)/ PET-CT}

PET/ PET-CT is routinely not done for detection of primary cancer. However, its gaining popularity for its role in pretreatment planning and follow-up. Its disadvantages include false negatives with borderline indeterminate ovarian tumors and false positives with conditions causing increased FDG uptake such as endometriosis, fibroids, and normal follicles in premenopausal women [5,8]. Increased FDG uptake in post menopausal women is abnormal. With regards to tumour recurrence detection, PET/ PET-CT is superior to CT and MRI with higher sensitivity and specificity $[9,10]$.

\section{BENIGN OVARIAN CYSTIC LESIONS}

\section{Functional/ Haemorrhagic Cysts}

Functional cysts on ultrasound have thin wall $(<3 \mathrm{~mm})$, are unilocular and with posterior accoustic enhancement [11]. Complex cysts may show reticulations or contain 
a heterogeneous haemorrhagic clot. Features favouring malignancy include- solid components, nodular septae, vascularity within the lesion and papillary projections [12]. In premenopausal women, ovarian cysts with uniform internal echoes, reticulations or septations may represent an endometriotic cyst or haemorrhagic cyst. A follow-up ultrasound should be performed after the next menstrual cycle or after one month [13]. A haemorrhagic cyst would resolve following the interval period, while an endometriotic cyst would persist or may even increase in size. On MRI functional cysts are hypointense on $\mathrm{T} 1$ weighted images (T1-WI) and hyperintense on T2 weighted images (T2-WI). Haemorrhagic cysts, due to its blood products appear hyperintense on T1$\mathrm{WI}$ and intermediate to hyperintense on T2-WI, which may be difficult to differentiate from endometriotic cysts [14].

\section{Polycystic Ovaries}

$5-10 \%$ of all women of reproductive age are affected by polycystic ovarian syndrome (PCOD) [15]. PCOD is characterized by menstrual irregularities, obesity, hirsuitism and sclerotic ovaries. However, not all women with USG features of polycystic ovaries have PCOD. Transvaginal Ultrasonography (TVS) is the gold standard, and the characteristic imaging feature is a string of pearls' appearance, where 10 or more tiny cystic follicles $(<10 \mathrm{~mm}$ diameter) are arranged in the periphery around a central stroma within a bulky ovary [16]. MRI is seldom used as it doesn't provide additional information. They're best seen on $\mathrm{T} 2-\mathrm{WI}$ where hyperintense cysts are seen in the periphery arranged around a central hypointense central stroma.

\section{Endometrioma}

Implantation of endometrial tissue outside the uterus is known as endometriosis. $80 \%$ of the cases are implanted in the ovaries [17]. Patients may be asymptomatic or present with dysmenorrhoea, pelvic pain and infertility. They have a varied presentation on USG ranging from a cyst with low level internal echoes to a complex mass with hyperechoic foci due to a cholesterol cleft or blood clot in the wall. On CT endometrioma may mimic a malignant lesion. On MRI, these lesions are very hyperintense on T1-WI , fat saturated T1-WI and intermediate to hypointense on T2-WI, due degradation products of haemoglobin in various stages and decreased free water content [18]. Endometrioma may also present as multiple hyperintense foci on T1-WI in both ovaries. Malignant transformation of endometrioma especially to endometroid or clear cell adenocarcinomas are seen in only less than 1\% of the cases, and appear as hypointense lesions on T2-WI with enhancing mural nodules [19].

\section{BENIGN EPITHELIAL OVARIAN TUMOR}

They're seen in the younger age group and primarily cystic, while their malignant counterparts are cystic with solid components [20]. Serous and mucinous cystadenomas are the two most common subtypes of benign epithelial neoplasms. Serous cystadenomas are mostly thin walled and unilocular [Table/Fig-5], very rarely multilocular and are usually bilateral. They're hypointense on T1-WI and hyperintense on T2-WI and show no significant post contrast enhancement. Mucinous cystadenomas are larger than serous cystadenomas, are multilocular (honeycomb pattern) [Table/Fig-6], with thin wall and septae without significant post contrast enhancement [21]. The MRI signal intensity (SI) of mucinous cystadenoma depends on the mucin content and maybe hypointense on T2-WI when dehydrated mucin is present.

An uncommon ovarian epithelial neoplasm is Cystadenofibroma, where fibrous stroma is the major component along with an epithelial lining. They're seen in premenopausal women and most are benign, and an accurate diagnosis avoids unnecessary surgery [22]. On imaging, 50\% are purely cystic, while the remaining are complex cystic lesions with solid component and/ or thick septa, mimicking malignancy [23]. On MR T2-WI, the solid components are hypointense (isointense to skeletal muscle), while the cystic components are hyperintense [24]. Another variable presentation is cyst wall partial/diffuse thickening with/without solid components on T2-WI, with the solid components showing post contrast enhancement.

Mature Cystic Teratoma is mostly seen in women $<45$ years of age. It comprises of tissues derived from all 3 embryonic germ cell layers, consisting of skin glands, hair follicles, sebaceous material and muscles. On imaging, they have a variable appearance, ranging from cystic to solid or mixed with predominantly fat components [Table/Fig-7]. The fat content on CT will show negative $\mathrm{HU}$ attenuation values, while on MRI they will be hyperintense on T1-WI and suppressed on T1 fat saturated images [21, 25].

\section{Malignant Cystic Ovarian Lesions}

On imaging malignant lesions of the ovaries may present as complex masses with solid-cystic areas. Features favouring malignancy include septations $(>3 \mathrm{~mm})$, thick irregular wall $(>3 \mathrm{~mm})$ and solid enhancing areas with areas of necrosis $[26,27]$. Ascites, lymphadenopathy, peritoneal and omental implants are other possible associated findings depending on the extent of the disease. When compared with Doppler USG and Contrast enhanced CT, MRI is more sensitive and specific [28].

Serous cystadenocarcinomas [Table/Fig-8], comprise 25\% of serous epithelial neoplasms and usually are homogenous with soft tissue density on CT and may show hypointense papillary projections on T2-WI, which prominently enhance after contrast administration. Other variable appearances include heterogeneity and calcifications. Serous 

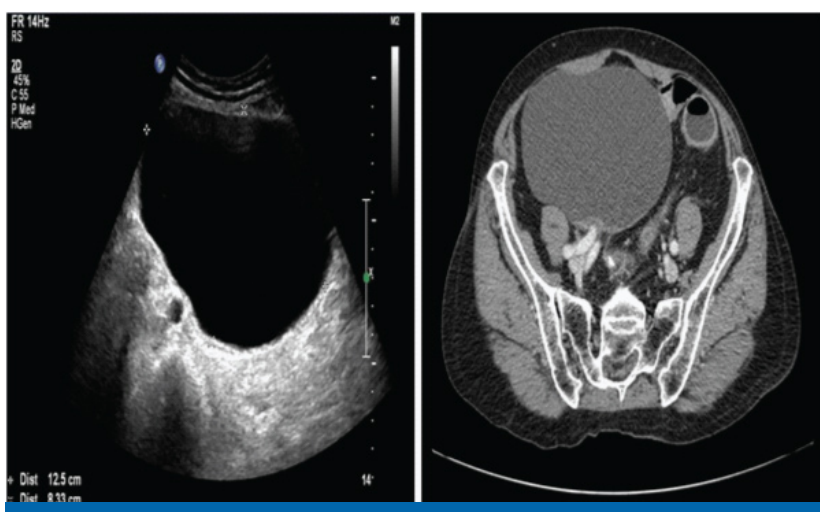

[Table/Fig-5]: Ultrasound and CT images showing a serous cystadenoma in a 48 years old female patient.
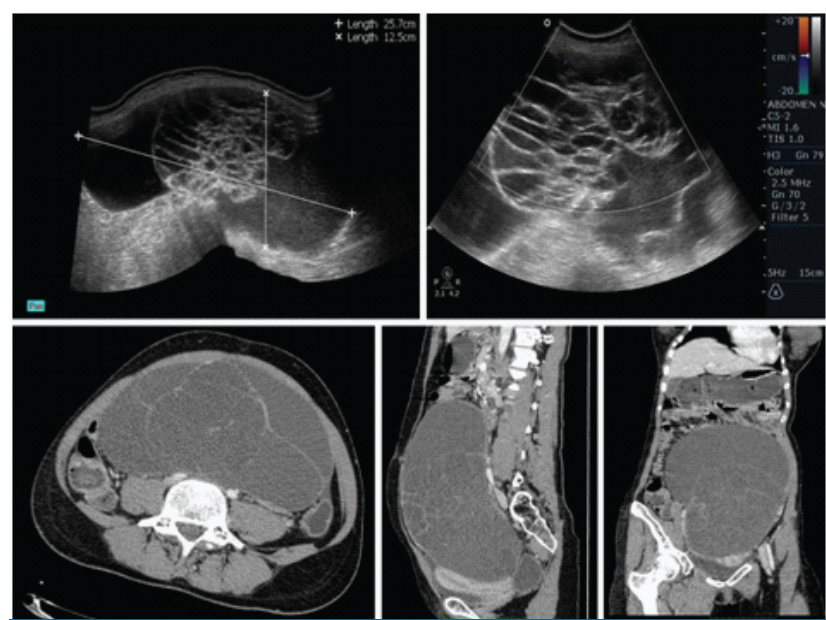

[Table/Fig-6]: Ultrasound and CT images showing a large cystic lesion with multiple septations. This was a case of mucinous cystadenoma.
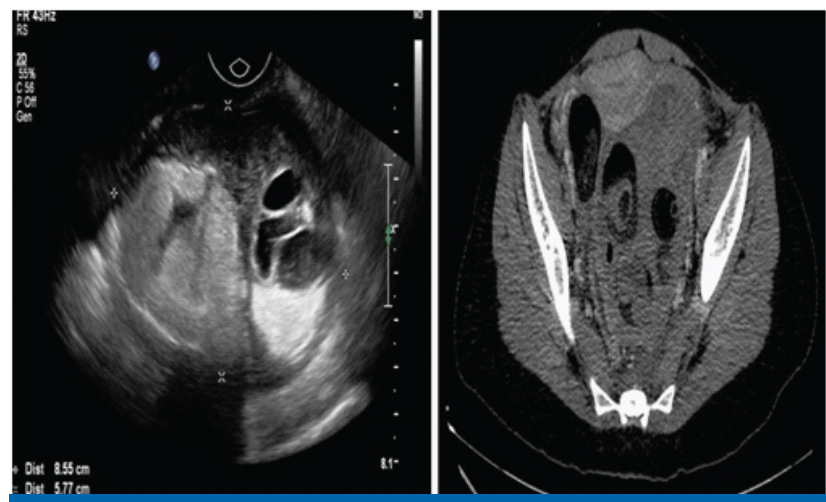

[Table/Fig-7]: Lesion showing echogenic areas on ultrasound and fat density areas on CT suggestive of mature cystic teratoma in 38 year old female patient.

cystadenocarcinomas are frequently associated bilateralism and peritoneal carcinomatosis [29].

Mucinous cystadenocarcinomas comprise $<10 \%$ of mucinous epithelial neoplasms. They're usually unilateral and have papillary projections and enhancing soft tissue components. These can rupture and cause pseudomyxomaperitonei.

Germ cell tumors [Table/Fig-9], constitute 15-20\% of all ovarian tumors and include the following subtypes: mature teratoma, immature teratoma, dysgerminoma, endodermal sinus tumor, embryonal carcinoma and choriocarcinoma. Among the several subtypes, mature teratoma is the most common and is benign. Enzyme markers like serum $\alpha$ FetoProtein (AFP) and human chorionic gonadotropin are raised in choriocarcinoma and help in the diagnosis. Endodermal sinus tumor/ Yolk sac tumor is mostly seen in $2^{\text {nd }}$ decade of life and is associated with elevated serum AFP. It's seen on USG as a heterogeneous solid-cystic mass with variable post contrast enhancement [29,30].

Granulosa cell tumors are the commonest malignant sex cord tumor comprising $<5 \%$ of all malignant ovarian tumors. They're associated with endocrine abnormalities such as menorrhagia, menstrual irregularities, and amenorrhea secondary to estrogen production by the tumor [28]. On CT/MRI they appear as a solid-cystic mass, resembling sometimes a honey comb pattern, where the spaces are filled with serous fluid or haemorrhage. The cystic component is usually hyperintense on $\mathrm{T} 2-\mathrm{WI}$ and the solid component is intermediate to hypointense. When haemorrhage is present, the cyst appear hyperintense on T1-WI \& T2-WI [3].

Ovarian metastases comprise $10 \%$ of all ovarian tumors [21]. Metastatic spread is either directly or via peritoneum.
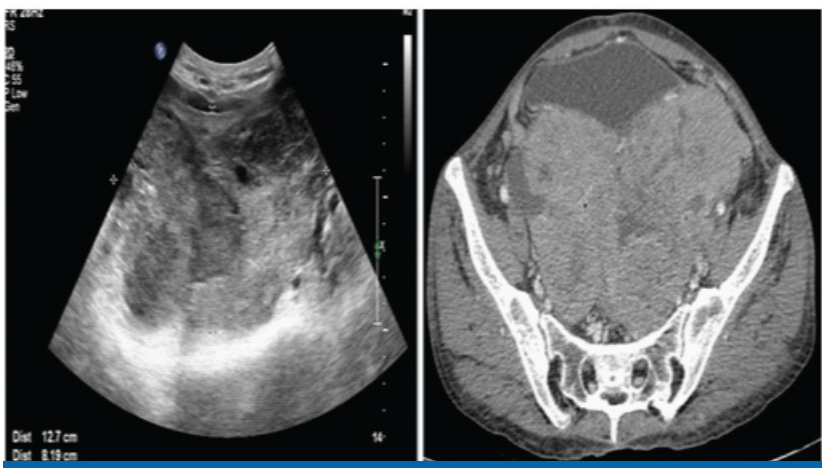

[Table/Fig-8]:Acaseofhistopathprovenserouscystadenocarcinoma in a 46 year old female patient.

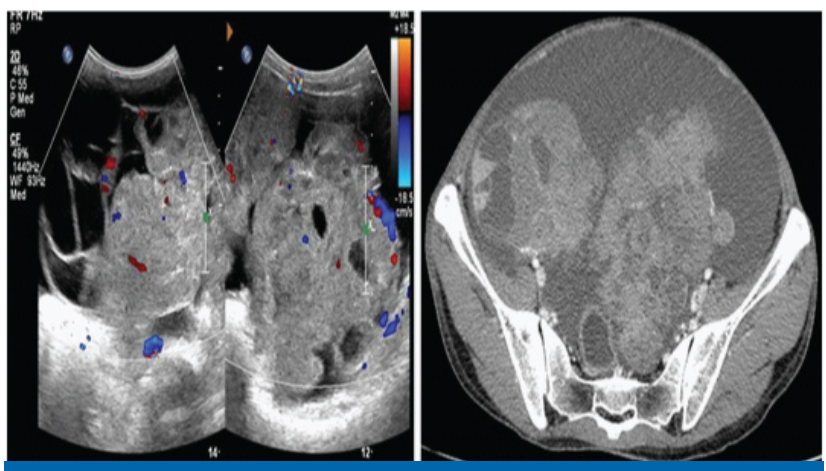

[Table/Fig-9]: A case of ovarian dysgerminoma in a 16 year old girl. 

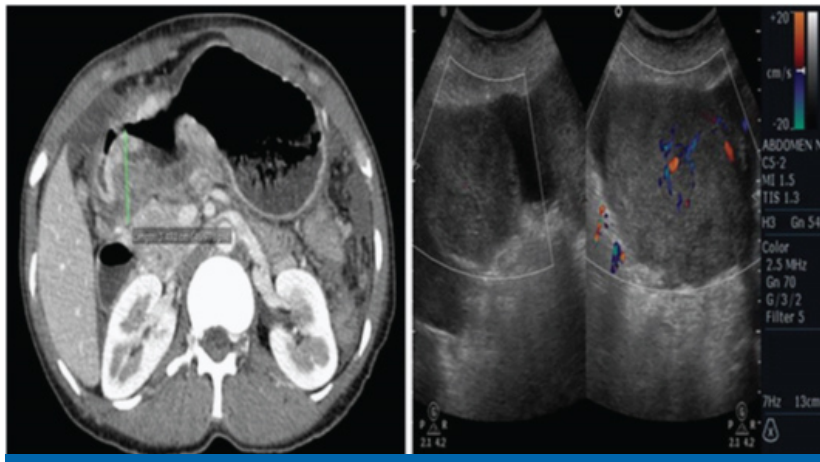

[Table/Fig-10]: CT showing Gastric wall thickening (15mm), with bilateral symmetric hypoechoic adnexal lesions on ultrasound. This was a proven case of Krukenberg tumor.

The most common primary being bowel, stomach and breast. Kruckenberg tumors refer to ovarian metastasis from gastric cancer, and are mostly bilateral and solid [Table/Fig-10], [31]. Metastases from colon carcinoma to ovaries commonly present as multiloculated cystic masses with a solid component [32]. On imaging the presence of thick mucinous content causes these lesions to appear as hypointense on T2-Wl.

\section{CONCLUSION}

Ovarian lesions comprise a spectrum from benign to malignant. Imaging plays a crucial role not only in aiding the diagnosis, but also in helping the surgeons for pre-op planning and in post treatment follow up. We are aware of the presence of several existing online literature regarding imaging based evaluation of ovarian neoplasms. However ,we feel ours is unique as there are very few articles regarding this subject based on the Indian population, and in addition we provide a unique algorithm based approach to these lesions which can help differentiate benign from malignant neoplasms and can obviate unwarranted surgery and therefore avoid unnecessary cost, stress and inconvenience to patients and their families.

\section{REFERENCES}

[1] Cancer facts and figures. Atlanta: American cancer society. 2010:19.

[2] Wasnik AP, Menias CO, Platt JF, Lalchandani UR, Bedi DG, Elsayes KM. Multimodality imaging of ovarian cystic lesions: Review with an imaging based algorithmic approach. World J Radiol. 2013;5(3):113-25.

[3] Togashi K. Ovarian cancer: the clinical role of US, CT, and MRI Eur Radiol. 2003;13Suppl 4:L87-104.

[4] Sohaib SA, Reznek RH. MR imaging in ovarian cancer. Cancer Imaging. 2007;7 Spec No A:S119-29.

[5] lyer VR, Lee SI. MRI, CT, and PET/CT for ovarian cancer detection and adnexal lesion characterization. AJR Am J Roentgenol. 2010;194(2):311-21. doi: 10.2214/AJR.09.3522.

[6] Kinkel K, Lu Y, Mehdizade A, Pelte MF, Hricak H. Indeterminate ovarian mass at US: incremental value of second imaging test for characterization--meta-analysis and Bayesian analysis. Radiology. 2005;236(1):85-94. Epub 2005 Jun 13.
[7] Adusumilli S, Hussain HK, Caoili EM, Weadock WJ, et al. MRI of sonographically indeterminate adnexal masses. AJR Am J Roentgenol. 2006;187(3):732-40.

[8] Fenchel S, Grab D, Nuessle K, Kotzerke J, Rieber A, et al. Asymptomatic adnexal masses: correlation of FDG PET and histopathologic findings. Radiology. 2002;223(3):780-88.

[9] Schwarz JK, Grigsby PW, Dehdashti F, Delbeke D. The role of 18F-FDG PET in assessing therapy response in cancer of the cervix and ovaries. J Nucl Med. 2009;50(Suppl 1):64S-73S. doi: 10.2967/jnumed.108.057257. Epub 2009 Apr 20.

[10] Gu P, Pan LL, Wu SQ, Sun L, Huang G. CA 125, PET alone, PET-CT, CT and MRI in diagnosing recurrent ovarian carcinoma: a systematic review and meta-analysis. Eur J Radiol. 2009;71(1):164-74. doi: 10.1016/j.ejrad.2008.02.019. Epub 2008 Apr 18.

[11] Jeong YY, Outwater EK, Kang HK. Imaging evaluation of ovarian masses. Radiographics. 2000;20(5):1445-70.

[12] Bailey CL, Ueland FR, Land GL, De Priest PD, et al. The malignant potential of small cystic ovarian tumors in women over 50 years of age. GynecolOncol. 1998;69(1):3-7.

[13] Levine D, Brown DL, Andreotti RF, Benacerraf B, et al. Management of asymptomatic ovarian and other adnexal cysts imaged at US: Society of Radiologists in Ultrasound Consensus Conference Statement. Radiology. 2010;256(3):943-54. doi: 10.1148/radiol.10100213. Epub 2010 May 26.

[14] Outwater E, Schiebler ML, Owen RS, Schnall MD. Characterization of hemorrhagic adnexal lesions with MR imaging: blinded reader study. Radiology. 1993;186(2):489-94.

[15] Dunaif A. Insulin resistance and the polycystic ovary syndrome: mechanism and implications for pathogenesis. Endocr Rev. 1997;18(6):774-800.

[16] Lakhani K, Seifalian AM, Atiomo WU, Hardiman P. Polycystic ovaries. Br J Radiol 2002; 75:9-16.

[17] Gerbie AB, Merrill JA. Pathology of endometriosis. ClinObstet Gynecol.1988; 31: 779-86.

[18] Takahashi K, Okada S, Okada M, Kitao M, Kaji Y, Sugimura $\mathrm{K}$. Magnetic resonance relaxation time in evaluating the cyst fluid characteristics of endometrioma. Hum Reprod. 1996 ;11(4):857-60.

[19] Tanaka YO, Yoshizako T, Nishida M, Yamaguchi M, Sugimura $\mathrm{K}$, Itai Y. Ovarian carcinoma in patients with endometriosis: MR imaging findings. AJR Am J Roentgenol. 2000 ;175(5):142330.

[20] Kawamoto S, Urban BA, Fishman EK. CT of epithelial ovarian tumors. Radiographics. 1999;19 Spec No:S85-102; quiz S26364.

[21] Jung SE, Lee JM, Rha SE, Byun JY, Jung JI, Hahn ST. CT and MR imaging of ovarian tumors with emphasis on differential diagnosis. Radiographics. 2002;22(6):1305-25.

[22] Sohaib SA, Sahdev A, Van Trappen P, Jacobs IJ, Reznek RH. Characterization of adnexal mass lesions on MR imaging. AJR Am J Roentgenol. 2003;180(5):1297-304.

[23] Exacoustos C, Romanini ME, Rinaldo D, Amoroso C, et al. Preoperative sonographic features of borderline ovarian tumors. Ultrasound Obstet Gynecol. 2005;25(1):50-59.

[24] Bent CL, Sahdev A, Rockall AG, Singh N, Sohaib SA, Reznek $\mathrm{RH}$. MRI appearances of borderline ovarian tumours. ClinRadiol. 2009;64(4):430-38.

[25] Talerman A. Germ Cell tumors of the ovary. In: Kurman RJ, editor. Blaustein's pathology of the female genital tract. New York, NY: Springer- Verlag, 2002:967-1033.

[26] Matsuoka Y, Ohtomo K, Araki T, Kojima K, Yoshikawa W, Fuwa S. MR imaging of clear cell carcinoma of the ovary. EurRadiol. 2001;11(6):946-51. 
[27] Occhipinti K. Computed tomography and magnetic resonance imaging of the ovary. In: Anderson JC, editor. Gynecologic imaging. London: Churchill Livingstone, 1999: 345-59.

[28] Kurtz AB, Tsimikas JV, Tempany CM, Hamper UM, Arger PH, et al. Diagnosis and staging of ovarian cancer: comparative values of Doppler and conventional US, CT, and MR imaging correlated with surgery and histopathologic analysis--report of the Radiology Diagnostic Oncology Group. Radiology. 1999;212(1):19-27.

[29] Pretorius ES, Outwater EK, Hunt JL, Siegelman ES. Magnetic resonance imaging of the ovary. Top MagnReson Imaging. 2001 ;12(2):131-46.
[30] Brammer HM $3^{\text {rd }}$, Buck JL, Hayes WS, Sheth S, Tavassoli FA. From the archives of the AFIP. Malignant germ cell tumors of the ovary: radiologic-pathologic correlation. Radiographics. 1990;10(4):715-24.

[31] Holtz F, Hart WR. Krukenbergtumors of the ovary: a clinicopathologic analysis of 27 cases. Cancer 1982; 50: 243847.

[32] Chang WC, Meux MD, Yeh BM, Qayyum A, Joe BN, Chen LM, et al. CT and MRI of adnexal masses in patients with primary nonovarian malignancy. AJR Am J Roentgenol. 2006;186(4):103945.

5. Professor \& Head, Department of Radio-Diagnosis, Father Muller Medical, Mangalore, Karnataka, India.

\section{NAME, ADDRESS, E-MAIL ID OF THE CORRESPONDING AUTHOR:}

Dr. Rishi Philip Mathew, Department of Radio-Diagnosis, Father Muller Medical College, Mangalore-575002, Karnataka, India.

E-mail: dr_rishimathew@yahoo.com

FINANCIAL OR OTHER COMPETING INTERESTS: None.

3. Senior Resident, Department of Radio-Diagnosis, Father Muller Medical, Mangalore, Karnataka, India.

4. Associate Professor, Department of Radio-Diagnosis, Father Muller Medical, Mangalore, Karnataka, India. 